\title{
Prevention of postoperative atrial fibrillation in open heart surgery patients by preoperative supplementation of $n-3$ polyunsaturated fatty acids: An updated meta-analysis
}

\author{
Simona Costanzo, MS, PhD, Veronica di Niro, BN, Augusto Di Castelnuovo, MS, PhD, \\ Francesco Gianfagna, MD, PhD, Maria Benedetta Donati, MD, PhD, Giovanni de Gaetano, MD, PhD, and \\ Licia Iacoviello, $\mathrm{MD}, \mathrm{PhD}$
}

\begin{abstract}
Background: Several randomized clinical trials evaluated whether preoperative supplementation of omega-3 (n-3) polyunsaturated fatty acids protects against postoperative atrial fibrillation after cardiac surgery, a condition associated with increased cardiac and cerebral mortality. However, their efficacy remains still controversial. An updated meta-analysis was performed to clarify if preoperative n-3 polyunsaturated fatty acid supplementation prevents postoperative atrial fibrillation in patients undergoing cardiac surgery.
\end{abstract}

\begin{abstract}
Methods: Articles were retrieved until November 2012 by screening electronic databases (PubMed, EMBASE, Web of Science, and Cochrane Central Register of Controlled Trials) and cross references. Two of us independently reviewed articles and agreed to select 8 randomized clinical trials. For each study, the incidence of atrial fibrillation in both the intervention and placebo groups was extracted to calculate odd ratio and $95 \%$ confidence intervals (CIs). Weighted study-specific estimates were combined using fixed (Mantel-Haenszel method) and random-effects (DerSimonian-Laird method) models.
\end{abstract}

Results: This meta-analysis includes 2687 patients (1337 in the intervention group) who underwent cardiac surgery. Pooled analysis using fixed-effects models showed a significant reduction (average, $16 \% ; 95 \% \mathrm{CI}$, $1 \%-29 \%$ ) in postoperative atrial fibrillation by preoperative $n-3$ polyunsaturated fatty acids. There was a low heterogeneity among studies $\left(P=.07\right.$ and $\left.\mathrm{I}^{2}=46 \%\right)$. By using a random-effects model, the reduction averaged $25 \%$ (odds ratio, $0.75 ; 95 \% \mathrm{CI}, 0.57-1.00 ; P=.05$ ). When isolated coronary artery bypass graft surgery was only considered ( 7 studies), a significant protection averaging $34 \%$ was observed in a fixed model (odds ratio, $0.66 ; 95 \%$ CI, $\left.0.50-0.87 ; P=.003 ; \mathrm{I}^{2}=26 \%, P=.23\right)$.

Conclusions: A preoperative supplementation of $n-3$ polyunsaturated fatty acids significantly prevents the occurrence of postoperative atrial fibrillation in patients undergoing cardiac surgery, in particular coronary artery bypass surgery. (J Thorac Cardiovasc Surg 2013;146:906-11)

Atrial fibrillation (AF) is the most common type of arrhythmia after cardiac surgery. The incidence of postoperative atrial fibrillation (POAF) ranges from $20 \%$ to $50 \%$ and depends on patient age, predisposing and intraoperative factors, complexity of the surgical procedure, and

From the Laboratorio di Epidemiologia Genetica ed Ambientale, Laboratori di Ricerca, Fondazione di Ricerca e Cura “Giovanni Paolo II," Università Cattolica, Campobasso, Italy.

This study was supported in part by the Italian Ministry of Health, Young Researchers Grant 2008-1146478 and by the Project "Malattie cardiovascolari: ruoli di fattori genetici, acquisiti, nuovi approcci terapeutici e condizioni organizzative ottimali per la produzione delle conoscenze" (D. MIUR n. 328 del 01/07/2010). This funding source had no involvement in study design; in the collection, analysis, and interpretation of data; or in the writing of the report and in authors' decision to submit the paper for publication.

Disclosures: Authors have nothing to disclose with regard to commercial support.

Received for publication Dec 12, 2012; revisions received Feb 11, 2013; accepted for publication March 6, 2013; available ahead of print April 15, 2013.

Address for reprints: Licia Iacoviello, MD, PhD, Laboratorio di Epidemiologia Genetica ed Ambientale, Laboratori di Ricerca, Fondazione di Ricerca e Cura

"Giovanni Paolo II," Università Cattolica, Campobasso, Italy (E-mail: licia. iacoviello@moli-sani.org).

0022-5223/\$36.00

Copyright (c) 2013 by The American Association for Thoracic Surgery

http://dx.doi.org/10.1016/j.jtcvs.2013.03.015 definitions and methods of detection of the arrhythmias. ${ }^{1-4}$ The POAF is associated with prolonged hospitalization (intensive care unit and hospital stays), increased total hospital costs, morbidity, and all-cause mortality. ${ }^{3-5}$

In addition to the traditional antiarrhythmic therapy, new and upstream (nonantiarrhythmic) therapies received increasing attention for preventing POAF. ${ }^{6,7}$ Among the latter therapies, omega-3 (n-3) polyunsaturated fatty acids (PUFAs), with their anti-inflammatory properties and antiarrhythmic effects, may be a valid candidate to reduce POAF incidence after open heart surgery. ${ }^{6}$

Recent meta-analyses ${ }^{8-10}$ and systematic reviews ${ }^{6,11}$ have evaluated whether preoperative supplementation of n-3 PUFA protects against POAF in patients undergoing cardiac surgery, but more recent studies have reported less conclusive data, so that there are still doubts about their real efficacy.

This updated meta-analysis of prospective randomized clinical trials was performed to better clarify if preoperative n-3 PUFA supplementation would prevent POAF after cardiac surgery. In addition, focus was paid to the effect of n-3 

Abbreviations and Acronyms
$\mathrm{AF}=$ atrial fibrillation
$\mathrm{CABG}=$ coronary artery bypass graft
$\mathrm{CI}=$ confidence interval
$\mathrm{n}-3=$ omega-3
OHS = open heart surgery
$\mathrm{OR}=$ odds ratio
POAF $=$ postoperative atrial fibrillation
PUFA $=$ polyunsaturated fatty acid
$\mathrm{RCT}=$ randomized controlled trial

PUFA on POAF after a specific type of surgery (ie, isolated coronary artery bypass graft [CABG] surgery).

\section{METHODS}

\section{Search Strategy}

Articles were retrieved until November 2012 by searching in PubMed, EMBASE, Web of Science, and Cochrane Central Register of Controlled Trials, using the following key words: omega 3 fatty acids, eicosapentaenoic acid, docosahexaenoic acid, fish oils, atrial fibrillation, cardiac surgery, cardiopulmonary bypass, open heart surgery, cardiac valve surgery, and coronary artery bypass graft, supplemented by references from the selected articles and by abstracts from congress proceedings, to minimize the publication bias. After a preliminary literature search, 156 publications were identified and, of these publications, by screening titles and text abstracts, 28 potentially relevant articles were selected (Figure 1).

The inclusion criteria were as follows: (1) the study design was a prospective randomized control trial, (2) the study population included patients undergoing an open heart surgery, (3) it was possible to extract quantitative data, and (4) $P O A F$ was defined as an episode of AF that lasted longer than 5 minutes and/or was clinically recognized. Taking into account these inclusion criteria, two of us (S.C. and V.d.N.) first independently reviewed and scored the 28 identified studies, then jointly excluded the articles irrelevant to the current analysis (Figure 1) and agreed on the final selection of 8 randomized clinical trials ${ }^{12-19}$ on efficacy of n-3 PUFA for the prevention of AF after open heart surgery.

\section{Quality Assessment}

The same 2 reviewers (S.C. and V.d.N.) independently assessed the methodological quality of included studies using the Jadad scale. ${ }^{20}$ Disagreements were resolved by discussion or involving a third reviewer (F.G.).

\section{Data Extraction and Data Analysis}

For each of the selected studies, the incidence of POAF in both the intervention and control groups was extracted to calculate the odd ratio (OR) and $95 \%$ confidence intervals (CIs). For the study of Saravanan et al, ${ }^{14}$ in which the authors used 2 definitions of POAF ( $\mathrm{AF} \geq 30$ seconds in the life card monitor recording and clinically recognized $\mathrm{AF}$ ), we only selected data concerning clinically recognized $\mathrm{AF}$, as used in all other randomized controlled trials (RCTs). Moreover, we obtained the incidence of POAF separately for type of cardiac surgery (CABG or valve replacement/repair) and type of CABG technique (on-pump/off-pump CABG) by directly contacting the authors of 4 RCTs. ${ }^{12,15,16,18}$ All analyses were performed using standard statistical procedures provided in RevMan5.1 (The Cochrane Collaboration, Oxford, United Kingdom). Weighted study-specific estimates were combined using fixed (Mantel-Haenszel method) and random (DerSimonian-Laird method) effects models. If statistically significant heterogeneity between studies was not identified, the fixed-effect estimate was preferentially used as a summary measure. The hypothesis that publication bias might have affected the validity of the estimates was tested by a funnel plot-based approach. A simple test of asymmetry of the funnel plot was used according to the method proposed by Egger et al. ${ }^{21}$

\section{RESULTS}

The baseline characteristics of the selected studies are shown in Table 1. Four studies ${ }^{12-14,17}$ included patients undergoing isolated CABG surgery, 1 included CABG with or without concomitant valve surgery, ${ }^{18}$ and 3 included CABG, cardiac valve surgery, or combined procedures ${ }^{15,16,19}$ (Table 1).

\section{n-3 PUFA and Prevention of POAF in Open Heart Surgery}

This meta-analysis includes 2687 patients (1337 in the n-3 PUFA-treated patients) who underwent open heart surgery. No evidence of publication bias was found using the Egger test $(P=.2)$. By using fixed-effects models, pooled analysis showed a significant reduction in POAF by preoperative n-3 PUFA supplementation (OR, 0.84; 95\% CI, $0.71-0.99 ; P=.04$ ) (Figure 2 and Table 2). There was a low heterogeneity among studies $(P=.07$ and $\left.\mathrm{I}^{2}=46 \%\right)$. By using a random-effects model, the result was as follows: OR, $0.75 ; 95 \% \mathrm{CI}, 0.57-1.00 ; P=.050$.

Sensitivity and subgroup analyses were performed to investigate the source of heterogeneity among studies.

\section{n-3 PUFA and Prevention of POAF According to Type of Surgery}

Data on patients who underwent isolated CABG surgery were extracted from 7 studies ${ }^{12-18}$ (1028 patients, Figure 2). For the studies of Heidarsdottir, ${ }^{15}$ Farquharson,,${ }^{16}$ and Sandesara, ${ }^{18}$ data on isolated CABG were obtained from the authors (Figure 3 and Table 2). No evidence of publication bias was found $(P=.92)$. Significant protection was observed in both a fixed-effects model (OR, 0.66 ; $95 \% \mathrm{CI}$, $0.50-0.87 ; P=.003 ; \mathrm{I}^{2}=26 \%, P=.23$ ) (Figure 3 ) and a random-effects model (OR, 0.66; 95\% CI, 0.47-0.92; $P=.01$ ).

The effect of PUFA supplementation was also investigated in a subgroup of studies on open heart surgeries (OHSs) (Table 2). In this sensitivity analysis, in which 3 studies ${ }^{15,16,19}$ considered indiscriminately patients who underwent $\mathrm{CABG}$, cardiac valve surgery, or combined procedures (Table 1), the effect of PUFA was as follows: OR, $0.92\left(95 \%\right.$ CI, 0.76-1.12;P = .40; $\mathrm{I}^{2}=0 \%$, $P=.38$ ). Moreover, data on patients who underwent a valve surgery or CABG combined with other cardiac surgery were extracted from 3 studies $^{15,16,18}$; however, their pooled analysis showed a high heterogeneity among studies and the few patients (64 n-3 PUFA-treated patients and 79 controls) limited the statistical power (Table 2).

Interestingly, the heterogeneity was clearly reduced within isolated CABG $\left(\mathrm{I}^{2}=26 \%\right)$ and OHS $\left(\mathrm{I}^{2}=0 \%\right)$ subgroups, indicating that a consistent part of the overall 


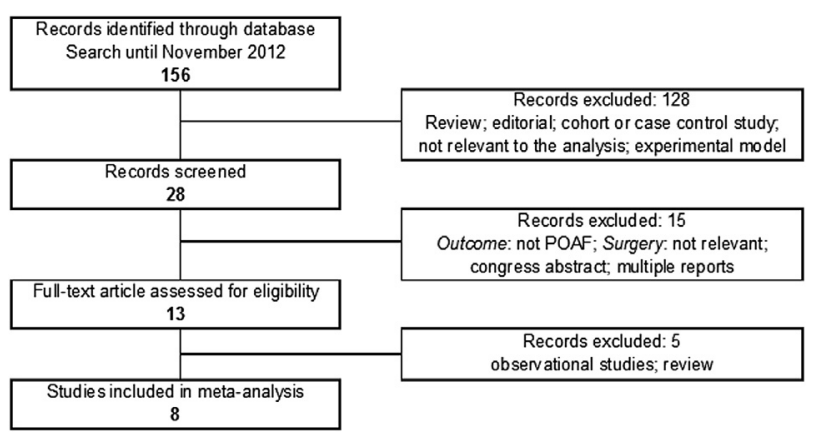

FIGURE 1. Flow chart of the selected studies. $P O A F$, Postoperative atrial fibrillation.

heterogeneity originated from the difference in the type of surgery $\left(\mathrm{I}^{2}=46 \%, P=.07\right)$. In addition, we performed a sensitivity analysis in 5 studies, ${ }^{12-14,16,17}$ only considering on-pump isolated CABG (294 n-3 PUFA-treated patients of a total of 575 patients), by using a random model (OR, $0.57 ; 95 \%$ CI, $0.32-1.01 ; P=.05 ; \mathrm{I}^{2}=54 \%, P=.07$ ) (Table 2).

\section{n-3 PUFA and Prevention of POAF According to Type of Placebo}

Table 1 also reports the type of placebo used in each selected study: usual care, ${ }^{12,17}$ olive,${ }^{14,15,19}$ soya, ${ }^{13}$ sunflower, ${ }^{16}$ or corn ${ }^{18}$ oils. There was no apparent beneficial effect of n-3 PUFA when the olive oil was used as a placebo compared with the other 2 subgroups (usual care and other vegetable oils), although $P$ for difference was equal to .13 among subgroups (Table 2).

TABLE 1. Characteristics of RCTs included in the meta-analysis

\begin{tabular}{|c|c|c|c|c|c|c|c|c|c|c|c|}
\hline Study & Country & $\begin{array}{c}\text { Type of } \\
\text { study }\end{array}$ & Surgery & $\begin{array}{c}\text { Total } \\
\text { no. of } \\
\text { patients }\end{array}$ & JQS & $\begin{array}{c}\text { Study } \\
\text { arm } \\
\end{array}$ & $\begin{array}{c}\text { No. of } \\
\text { patients } \\
\end{array}$ & $\begin{array}{c}\text { Age, } \\
\text { mean } \pm \text { SD }\end{array}$ & $\begin{array}{c}\text { Men, } \\
\text { No. }(\%) \\
\end{array}$ & Intervention & $\begin{array}{c}\text { POAF } \\
\text { rate, } \\
\text { No. }(\%) \\
\end{array}$ \\
\hline \multirow[t]{2}{*}{ Calò et al, ${ }^{12} 2005$} & Italy & $\mathrm{R}, \mathrm{OL}$ & CABG & 160 & 3 & Control & 81 & $64.9 \pm 9.1$ & $68(84)$ & Usual care & $27(33.3)$ \\
\hline & & & & & & Treatment & 79 & $66.2 \pm 8.0$ & $68(86)$ & $\begin{array}{l}\text { n-3 PUFA: } 2 \mathrm{~g} / \mathrm{d} \\
\text { (EPA:DHA, } \\
1: 2)\end{array}$ & $12(15.2)$ \\
\hline \multirow[t]{2}{*}{ Heidt et al, ${ }^{13} 2009$} & Germany & $\mathrm{R}, \mathrm{DB}$ & CABG & 102 & 4 & Control & 50 & $68.1 \pm 9.7$ & $32(64)$ & $\begin{array}{l}\text { Soya oil: } 100 \\
\text { mg/kg per day }\end{array}$ & $15(30.0)$ \\
\hline & & & & & & Treatment & 52 & $64.7 \pm 12.8$ & $38(73)$ & $\begin{array}{l}\text { Fish oil: } 100 \\
\text { mg/kg per day } \\
\text { (EPA:DHA, } \\
0.9: 1)\end{array}$ & $9(17.3)$ \\
\hline \multirow{2}{*}{$\begin{array}{l}\text { Saravanan et al, }{ }^{14} \\
2009\end{array}$} & United & $\mathrm{R}, \mathrm{DB}$ & CABG & 103 & 5 & Control & 51 & 68 (64-73) & $42(82)$ & Olive oil: $2 \mathrm{~g} / \mathrm{d}$ & $18(35.3)$ \\
\hline & Kingdom & & & & & Treatment & 52 & $64(58-71)^{*}$ & $40(77)$ & $\begin{array}{l}\text { n-3 PUFA: } 2 \mathrm{~g} / \mathrm{d} \\
\text { (EPA:DHA, } \\
1.2: 1 \text { ) }\end{array}$ & $22(42.3)$ \\
\hline \multirow{2}{*}{$\begin{array}{l}\text { Heidarsdottir et al, }{ }^{15} \\
\quad 2010\end{array}$} & Iceland & $\mathrm{R}, \mathrm{DB}$ & OHS & 168 & 4 & Control & 85 & $67(43-82)$ & $65(77)$ & Olive oil: $2 \mathrm{~g} / \mathrm{d}$ & $46(54.1)$ \\
\hline & & & & & & Treatment & 83 & $67(45-82)^{*}$ & $68(82)$ & $\begin{array}{r}1.24 \mathrm{~g} / \mathrm{d} \text { EPA; } \\
1 \mathrm{~g} / \mathrm{d} \text { DHA }\end{array}$ & $45(54.2)$ \\
\hline \multirow[t]{2}{*}{$\begin{array}{l}\text { Farquharson et al, }{ }^{16} \\
\quad 2011\end{array}$} & Australia & $\mathrm{R}, \mathrm{DB}$ & OHS & 194 & 5 & Control & 97 & $64.0 \pm 10.0$ & $62(64)$ & $\begin{array}{l}\text { Sunflower oil: } \\
15 \mathrm{~mL} / \mathrm{d}\end{array}$ & $47(48.4)$ \\
\hline & & & & & & Treatment & 97 & $64.0 \pm 11.0$ & $80(82)$ & $\begin{array}{l}\text { Fish oil: } 15 \mathrm{~mL} / \mathrm{d} \\
\text { (EPA:DHA, } \\
1.42: 1)\end{array}$ & $36(37.1)$ \\
\hline \multirow[t]{2}{*}{ Sorice et al, ${ }^{17} 2011$} & Italy & $\mathrm{R}$ & CABG & 201 & 3 & Control & 105 & $63.0 \pm 9.0$ & $88(84)$ & NR (usual care) & $24(22.9)$ \\
\hline & & & & & & Treatment & 96 & $64.0 \pm 10.0$ & $76(79)$ & $\begin{array}{l}\text { n-3 PUFA: } 2 \text { g/d } \\
\text { (EPA:DHA, } \\
1: 2)\end{array}$ & $11(11.4)$ \\
\hline \multirow{2}{*}{$\begin{array}{l}\text { Sandesara et al, }{ }^{18} \\
\quad 2012\end{array}$} & United & $\mathrm{R}, \mathrm{DB}$ & $\mathrm{CABG} \dagger$ & 243 & 4 & Control & 123 & $62.0 \pm 11.4$ & $102(83)$ & Corn oil: $2 \mathrm{~g} / \mathrm{d}$ & $40(32.5)$ \\
\hline & States & & & & & Treatment & 120 & $63.4 \pm 9.5$ & $94(78)$ & $\begin{array}{l}\text { n-3 PUFA: } 4 \mathrm{~g} / \mathrm{d} \\
\text { (EPA:DHA, } \\
1.24: 1 \text { ) }\end{array}$ & $36(30.0)$ \\
\hline \multirow{2}{*}{$\begin{array}{l}\text { Mozaffarian et al, }{ }^{19} \\
2012\end{array}$} & Argentina, & $\mathrm{R}, \mathrm{DB}$ & OHS & 1516 & 5 & Control & 758 & $63.6 \pm 12.4$ & $543(72)$ & Olive oil: NR & $233(30.7)$ \\
\hline & $\begin{array}{l}\text { Italy, } \\
\text { United } \\
\text { States }\end{array}$ & & & & & Treatment & 758 & $63.8 \pm 12.6$ & $551(73)$ & $\begin{array}{l}\text { n-3 PUFA: } 2-4 \\
\text { g/d (EPA:DHA, } \\
\text { 1.24:1) }\end{array}$ & $227(30.0)$ \\
\hline
\end{tabular}

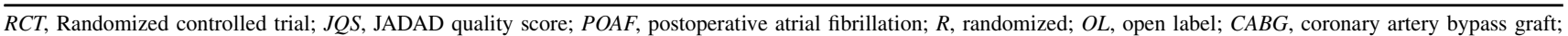
n-3 PUFA, omega-3 polyunsaturated fatty acids; EPA, eicosapentaenoic acid; $D H A$, docosahexaenoic acid; $D B$, double blinding; $O H S$, open heart surgery; NR, not reported; $S D$, standard deviation. *Median (25th and 75 th percentiles) of age. †Isolated CABG or combined with cardiac valve surgery. 


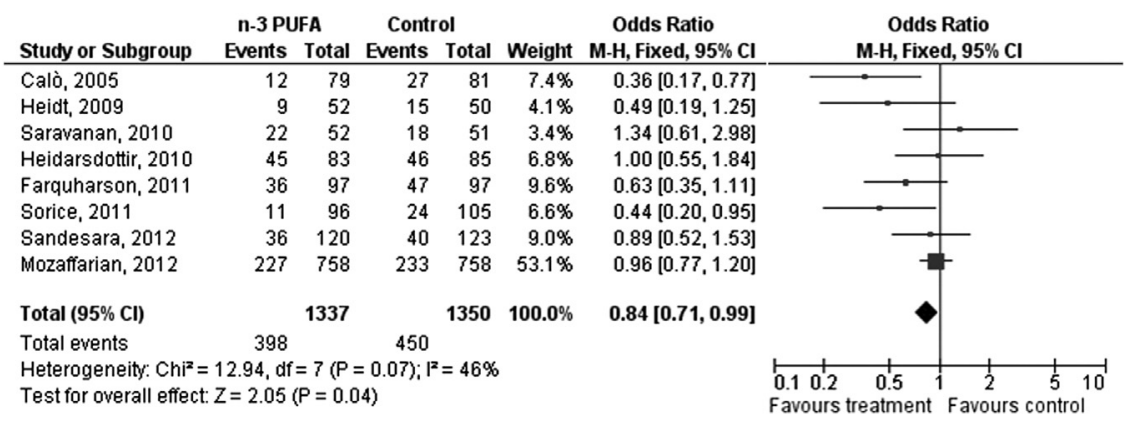

FIGURE 2. Omega-3 polyunsaturated fatty acids ( $n-3$ PUFA) and prevention of postoperative atrial fibrillation in open heart surgery. $M$ - $H$, MantelHaenszel; $C I$, confidence interval.

A sensitivity analysis on methodological quality of studies has not been performed, because no study was of a low quality (Jadad score $\leq 2$, Table 1 ).

\section{DISCUSSION}

The present meta-analysis on the effect of preoperative n-3 PUFA supplementation in POAF prevention after cardiac surgery was undertaken to overcome some remarkable limitations of previous ones, such as the availability of few studies only, their small sample size, ${ }^{8-10,22,23}$ and several sources of heterogeneity, such as the type of surgery and/ or of placebo. Consequently, the results of previous metaanalyses had low statistical power and rather inconclusive findings.

The current meta-analysis was based on 2687 (n-3 PUFA treated, 1337) patients from 8 studies and included 2 recent randomized clinical trials, ${ }^{18,19} 1$ of which had enrolled a consistent number of patients. ${ }^{19}$ Preoperative n-3 PUFA supplementation significantly reduced by an average of $16 \%$ the odds of POAF after open heart surgery (Figure 2), a result in line with a previous smaller meta-analysis. ${ }^{9}$ The observed reduction was more than double (average, 34\%; being basal incidence of POAF, $33.5 \%$ ) when only patients undergoing isolated $\mathrm{CABG}$ were considered. The latter finding, which was obtained by pooling all studies but the largest one, which did not include patients with $\mathrm{CABG},{ }^{19}$ represents the main novelty of the present meta-analysis (Figure 3 and Table 2).

The pathophysiological characteristics of POAF after open heart surgery are multifactorial, but not well known yet. Several factors are considered to be associated with the development of POAF: predisposing factors, such as advanced age, hypertension, diabetes, obesity, and metabolic syndrome; intraoperative factors, such as surgical injury, atrial ischemia, pulmonary vein vent, venous cannula, and acute volume changes; and postoperative factors, such as volume overload, increased afterload, and hypotension. The main common pathways of all these factors are inflammation and oxidative stress. ${ }^{1,24,25}$

Current guidelines recommend the use of antiarrhythmic drugs to decrease the risk of POAF after cardiac surgery. However, the patient is not fully protected from POAF by using

TABLE 2. Sensitivity analyses according to type of surgery and placebo

\begin{tabular}{|c|c|c|c|c|c|c|c|c|c|c|}
\hline \multirow[b]{2}{*}{ Subgroup } & \multirow[b]{2}{*}{$\begin{array}{l}\text { No. of } \\
\text { studies }\end{array}$} & \multicolumn{2}{|c|}{ n-3 PUFA } & \multicolumn{2}{|c|}{ Control } & \multirow[b]{2}{*}{ OR $(95 \%$ CI $)$} & \multirow[b]{2}{*}{$\begin{array}{c}P \\
\text { value }\end{array}$} & \multirow[b]{2}{*}{ Model } & \multirow[b]{2}{*}{$\mathbf{I}^{2}$ value, $\%$} & \multirow[b]{2}{*}{$\begin{array}{c}P \text { value for } \\
\text { heterogeneity }\end{array}$} \\
\hline & & $\begin{array}{l}\text { POAF } \\
\text { events }\end{array}$ & Total & $\begin{array}{l}\text { POAF } \\
\text { events }\end{array}$ & Total & & & & & \\
\hline All studies & 8 & 398 & 1337 & 450 & 1350 & $\begin{array}{l}0.84(0.71-0.99) \\
0.75(0.57-1.00)\end{array}$ & $\begin{array}{l}.04 \\
.05\end{array}$ & $\begin{array}{l}\mathrm{FE} \\
\mathrm{RE}\end{array}$ & 46 & .07 \\
\hline \multicolumn{11}{|l|}{ Type of surgeries } \\
\hline OHS & 3 & 308 & 938 & 326 & 758 & $0.92(0.76-1.12)$ & .4 & FE & 0 & .38 \\
\hline Isolated CABG & 7 & 132 & 515 & 172 & 513 & $0.66(0.50-0.87)$ & .003 & $\mathrm{FE}$ & 26 & .23 \\
\hline On-pump isolated CABG & 5 & 70 & 294 & 95 & 281 & $\begin{array}{l}0.59(0.41-0.85) \\
0.57(0.32-1.01)\end{array}$ & $\begin{array}{l}.005 \\
.05\end{array}$ & $\begin{array}{l}\mathrm{FE} \\
\mathrm{RE}\end{array}$ & 54 & .07 \\
\hline $\begin{array}{l}\text { Valve surgery or CABG combined } \\
\text { with other cardiac surgeries }\end{array}$ & 3 & 39 & 64 & 45 & 79 & $\begin{array}{l}1.15(0.59-2.24) \\
1.48(0.39-5.54)\end{array}$ & $\begin{array}{l}.67 \\
.56\end{array}$ & $\begin{array}{l}\mathrm{FE} \\
\mathrm{RE}\end{array}$ & 69 & .04 \\
\hline \multicolumn{11}{|l|}{ Type of placebo } \\
\hline Usual care & 2 & 23 & 175 & 51 & 186 & $0.40(0.23-0.68)$ & .0009 & FE & 0 & .72 \\
\hline Olive oil & 3 & 294 & 893 & 279 & 894 & $0.99(0.81-1.21)$ & .91 & FE & 0 & .73 \\
\hline Other vegetal oils & 3 & 81 & 269 & 102 & 270 & $0.71(0.49-1.01)$ & .06 & FE & 0 & .49 \\
\hline
\end{tabular}

n-3 PUFA, Omega-3 polyunsaturated fatty acids; $P O A F$, postoperative atrial fibrillation; $O R$, odds ratio; $C I$, confidence interval; $F E$, fixed effect; $R E$, random effect; $O H S$, open heart surgery; $C A B G$, coronary artery bypass graft. 


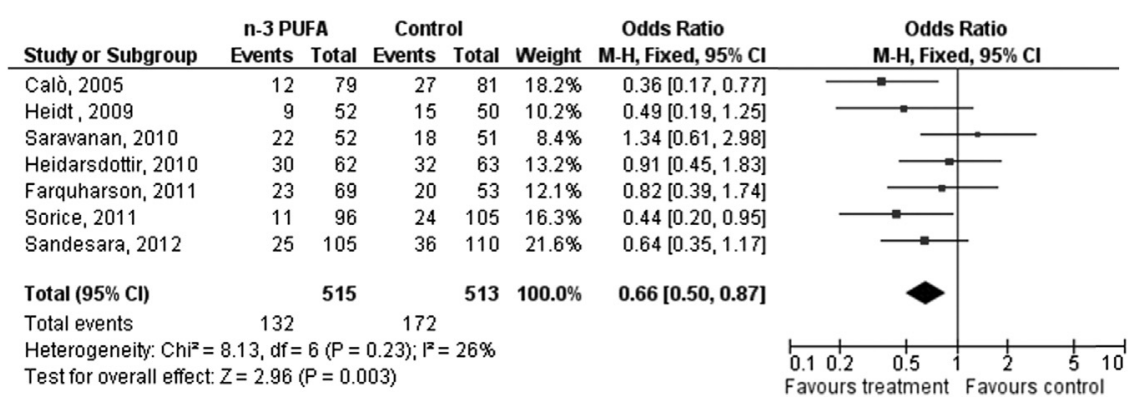

FIGURE 3. Omega-3 polyunsaturated fatty acids ( $n-3$ PUFA) and prevention of postoperative atrial fibrillation in isolated coronary artery bypass graft surgery. $M-H$, Mantel-Haenszel; $C I$, confidence interval.

only these agents; thus, newer therapies (nonantiarrhythmic drugs) for the management of atrial fibrillation are needed to be used in combination with them. ${ }^{1,6}$ Recently, the efficacy of several agents (drugs or nutraceuticals) in preventing POAF have been investigated. Among nonantiarrhythmic drugs, preoperative colchicine use (Colchicine for the Prevention of the Postpericardiotomy Syndrome substudy $)^{26}$ showed a reduction of relative risk of $45 \%$ in POAF occurrence, corticosteroids were associated with a reduction of relative risk of $26 \%$ to $58 \%,{ }^{6}$ and a recent systematic review concluded that preoperative statin therapy is also effective. ${ }^{27}$

Focusing on nutraceutical agents, n-3 PUFAs have been studied more frequently than others: the beneficial effect of a preoperative supplementation of n-3 PUFA on POAF is likely explained by the documented anti-inflammatory activity of PUFA. ${ }^{28-31}$ Experimental studies have also suggested a direct potential antiarrhythmic effect of $n-3$ PUFA. ${ }^{6,28,32}$ However, a diet rich in fish oil might have both proarrhythmic and antiarrhythmic proprieties, depending on the background of arrhythmia mechanisms and their vulnerable parameters. ${ }^{33,34}$

During $\mathrm{CABG}$, and other OHSs, a stronger and persistent stimulation of inflammation is likely to occur, due to both the nature of the disease ${ }^{35}$ and the influence of the operation techniques. ${ }^{36}$ Regarding our findings, the beneficial effect of fish oil supplementation in reducing POAF could be more easily detectable in patients undergoing CABG compared with conditions characterized by a lower-grade inflammatory reaction.

Interestingly, sensitivity analysis suggests that the efficacy of n-3 PUFA supplementation would vary in relation to the placebo used in the trial. Indeed, its efficacy was somewhat higher when compared with usual care, rather than with olive or other oils, a nonsignificant difference, however. One possible explanation is that corn, sunflower, and olive oil supplementation, because of their antioxidant content, could be associated with increased long-chain n-3 PUFA levels in plasma and red blood cell membranes, independently of fish oil intake. ${ }^{37,38}$

There are, however, some limitations of our metaanalysis owing to the relatively few and the heterogeneity of selected RCTs and the unfeasibility to perform sensitivity analysis for different dietary habits (eg, low or high fish intake), antiarrhythmic or other cardiovascular drug use, or other preoperative variables. Eussen et $\mathrm{al}^{39}$ suggested that statin treatment modifies the effects of n-3 PUFA on the incidence of major cardiovascular events; as in statin users, n-3 PUFA supplementation had no additive effect on major cardiovascular events. In addition to their effects on blood lipids, statins reportedly share with n-3 PUFA some anti-inflammatory effects, improve endothelial function, and inhibit platelet aggregation. ${ }^{40}$ Furthermore, differences in PUFA formulations and dosage and in the duration of supplementation among the studies did not allow the establishment of the optimal dose(s) of PUFAs endowed with their anti-arrhythmic effect. The trial with the largest sample size,${ }^{19}$ contributing half of the total weight of the studies included in our meta-analysis, failed to show any significant effect of PUFA (OR, 0.96; 95\% CI, 0.77-1.20). However, this trial included many open heart surgeries (cardiac valve surgery or combined procedures) and used olive oil as a placebo. Moreover, this was also the most recent study and many patients might have benefited from state-of-the-art treatments, making any added benefit from the omega 3 supplementation more difficult to detect. ${ }^{41}$

A major problem this meta-analysis shares with other similar statistical approaches remains that of the weight to be given to several smaller clinical trials, resulting in a pooled beneficial effect of n-3 PUFA in respect to a single larger trial reporting no significant benefits. In addition, our meta-analysis is limited by the heterogeneity of the studies (type of surgery or placebo) and the lack of availability of additional data on preoperative characteristics of enrolled patients. In the future, the effect on POAF of preoperative supplementation of n-3 PUFA should better be studied in a well-characterized patient population undergoing a single type of cardiac surgery procedure.

In conclusion, keeping in mind the limitations previously mentioned, a preoperative supplementation of n-3 PUFA to patients undergoing isolated CABG surgery significantly prevents the occurrence of POAF after an isolated CABG surgery. 
We thank our colleagues, Leonardo Calò (Department of Cardiac Disease, San Filippo Neri Hospital, Rome, Italy), Olafur S. Indridason (Landspidali University Hospital, Reykjavik, Iceland), Robert G. Metcalf (Centre for Heart Rhythm Disorders I, University of Adelaide, Australia), and Chirag M. Sandesara (Virginia Cardiovascular Associates, Manassas, Va) for making available data on CABG subgroups of their patients.

\section{References}

1. Echahidi N, Pibarot P, O'Hara G, Mathieu P. Mechanisms, prevention, and treatment of atrial fibrillation after cardiac surgery. J Am Coll Cardiol. 2008;51: 793-801.

2. Maisel WH, Rawn JD, Stevenson WG. Atrial fibrillation after cardiac surgery. Ann Intern Med. 2001;135:1061-73.

3. Banach M, Rysz J, Drozdz JA, Okonski P, Misztal M, Barylski M, et al. Risk factors of atrial fibrillation following coronary artery bypass grafting: a preliminary report. Circ J. 2006;70:438-41.

4. Mathew JP, Parks R, Savino JS, Friedman AS, Koch C, Mangano DT, et al., Multi Center Study of Perioperative Ischemia Research Group. Atrial fibrillation following coronary artery bypass graft surgery: predictors, outcomes, and resource utilization. JAMA. 1996;276:300-6.

5. Villareal RP, Hariharan R, Liu BC, Kar B, Lee VV, Elayda M, et al. Postoperative atrial fibrillation and mortality after coronary artery bypass surgery. $J$ Am Coll Cardiol. 2004;43:742-8

6. Savelieva I, Kakouros N, Kourliouros A, Camm AJ. Upstream therapies for management of atrial fibrillation: review of clinical evidence and implications for European Society of Cardiology guidelines, part I: primary prevention. Europace. 2011;13:308-28.

7. Burgess DC, Kilborn MJ, Keech AC. Interventions for prevention of postoperative atrial fibrillation and its complications after cardiac surgery: a metaanalysis. Eur Heart J. 2006;27:2846-57.

8. Liu T, Korantzopoulos P, Shehata M, Li G, Wang X, Kaul S. Prevention of atrial fibrillation with omega-3 fatty acids: a meta-analysis of randomised clinical trials. Heart. 2011;97:1034-40.

9. He Z, Yang L, Tian J, Yang K, Wu J, Yao Y. Efficacy and safety of omega-3 fatty acids for the prevention of atrial fibrillation: a meta-analysis. Can J Cardiol. 2013;29:196-203.

10. Takagi H, Umemoto T. Preoperative n-3 polyunsatured fatty acids do not reduce postoperative atrial fibrillation in cardiac surgery. Angiology. 2011;62:276-7.

11. Andreasen JJ, Schmidt EB. Therapeutic potential of marine $n-3$ fatty acids in CABG patients. Curr Opin Pharmacol. 2012;12:142-6.

12. Calò L, Bianconi L, Colivicchi F, Lamberti F, Loricchio ML, de Ruvo E, et al. N-3 fatty acids for the prevention of atrial fibrillation after coronary artery bypass surgery: a randomized, controlled trial. J Am Coll Cardiol. 2005;45:1723-8.

13. Heidt MC, Vician M, Stracke SK, Stadlbauer T, Grebe MT, Boening A, et al. Beneficial effects of intravenously administered N-3 fatty acids for the prevention of atrial fibrillation after coronary artery bypass surgery: a prospective randomized study. Thorac Cardiovasc Surg. 2009;57:276-80.

14. Saravanan P, Bridgewater B, West AL, O'Neill SC, Calder PC, Davidson NC. Omega-3 fatty acid supplementation does not reduce risk of atrial fibrillation after coronary artery bypass surgery: a randomized, double-blind, placebo controlled clinical trial. Circ Arrhythm Electrophysiol. 2009;3:46-53.

15. Heidarsdottir R, Arnar DO, Skuladottir GV, Torfason B, Edvardsson V, Gottskalksson G, et al. Does treatment with n-3 polyunsaturated fatty acids prevent atrial fibrillation after open heart surgery? Europace. 2010;12:356-63.

16. Farquharson AL, Metcalf RG, Sanders P, Stuklis R, Edwards JR, Gibson RA, et al. Effect of dietary fish oil on atrial fibrillation after cardiac surgery. $\mathrm{Am}$ J Cardiol. 2011;108:851-6.

17. Sorice M, Tritto FP, Sordelli C, Gregorio R, Piazza L. N-3 polyunsaturated fatty acids reduces post-operative atrial fibrillation incidence in patients undergoing "onpump" coronary artery bypass graft surgery. Monaldi Arch Chest Dis. 2011;7:93-8.

18. Sandesara CM, Chung MK, Van Wagoner DR, Barringer TA, Allen K, Ismail HM, et al. Randomized, placebo-controlled trial of omega-3 fatty acids for inhibition of supraventricular arrhythmias after cardiac surgery: the FISH trial. J Am Heart Assoc. 2012;1:e00547.
19. Mozaffarian D, Marchioli R, Macchia A, Silletta MG, Ferrazzi P, Gardner TJ, et al. Fish oil and postoperative atrial fibrillation: the Omega-3 Fatty Acids for Prevention of Post-operative Atrial Fibrillation (OPERA) randomized trial. JAMA. 2012;308:2001-11.

20. Jadad AR, Moore RA, Carroll D, Jenkinson C, Reynolds DJ, Gavaghan DJ, et al Assessing the quality of reports of randomized clinical trials: is blinding necessary? Control Clin Trials. 1996;17:1-12

21. Egger M, Davey Smith G, Schneider M, Minder C. Bias in meta-analysis detected by a simple, graphical test. BMJ. 1997;315:629-34.

22. Benedetto U, Angeloni E, Melina G, Danesi TH, Di Bartolomeo R, Lechiancole A, et al. n-3 Polyunsaturated fatty acids for the prevention of postoperative atrial fibrillation: a meta-analysis of randomized controlled trials J Cardiovasc Med. 2013;14:104-9.

23. Armaganijan L, Lopes RD, Healey JS, Piccini JP, Nair GM, Morillo CA. Do omega-3 fatty acids prevent atrial fibrillation after open heart surgery? a metaanalysis of randomized controlled trials. Clinics (Sao Paulo). 2011;66:1923-8.

24. Gaudino M, Andreotti F, Zamparelli R, Di Castelnuovo A, Nasso G, Burzotta F et al. The $-174 \mathrm{G} / \mathrm{C}$ interleukin-6 polymorphism influences postoperative interleukin-6 levels and postoperative atrial fibrillation: is atrial fibrillation an inflammatory complication? Circulation. 2003;108(suppl 1):II195-9.

25. Elahi MM, Flatman S, Matata BM. Tracing the origins of postoperative atria fibrillation: the concept of oxidative stress-mediated myocardial injury phenomenon. Eur J Cardiovasc Prev Rehabil. 2008;15:735-41.

26. Imazio M, Brucato A, Ferrazzi P, Rovere ME, Gandino A, Cemin R, et al. Colchicine reduces postoperative atrial fibrillation: results of the Colchicine for the Prevention of the Postpericardiotomy Syndrome (COPPS) atrial fibrillation substudy. Circulation. 2011;124:2290-5.

27. Liakopoulos OJ, Choi YH, Kuhn EW, Wittwer T, Borys M, Madershahian N, et al. Statins for prevention of atrial fibrillation after cardiac surgery: a systematic literature review. J Thorac Cardiovasc Surg. 2009;138:678-86.e1.

28. Mozaffarian D, Wu JH. Omega-3 fatty acids and cardiovascular disease: effects on risk factors, molecular pathways, and clinical events. J Am Coll Cardiol. 2011; 58:2047-67

29. Rangel-Huerta OD, Aguilera CM, Mesa MD, Gil A. Omega-3 long-chain polyunsaturated fatty acids supplementation on inflammatory biomakers: a systematic review of randomised clinical trials. Br J Nutr. 2012;107(suppl 2):S159-70.

30. De Lorgeril M. Essential polyunsaturated fatty acids, inflammation, atherosclerosis and cardiovascular diseases. Subcell Biochem. 2007;42:283-97.

31. Calder PC. n-3 Polyunsaturated fatty acids, inflammation, and inflammatory diseases. Am J Clin Nutr. 2006;83(6 Suppl):1505S-19S.

32. Leaf A, Kang JX, Xiao YF, Billman GE. Clinical prevention of sudden cardiac death by n-3 polyunsaturated fatty acids and mechanism of prevention of arrhythmias by $\mathrm{n}-3$ fish oils. Circulation. 2003;107:2646-52.

33. Coronel R, Wilms-Schopman FJ, Den Ruijter HM, Belterman CN, Schumacher CA, Opthof T, et al. Dietary n-3 fatty acids promote arrhythmias during acute regional myocardial ischemia in isolated pig hearts. Cardiovasc Res. 2007;73:386-94.

34. Den Ruijter HM, Berecki G, Opthof T, Verkerk AO, Zock PL, Coronel R. Proand antiarrhythmic properties of a diet rich in fish oil. Cardiovasc Res. 2007; 73:316-25.

35. Ross R. Atherosclerosis: an inflammatory disease. N Engl J Med. 1999;340: 115-26.

36. Apostolakis E, Filos KS, Koletsis E, Dougenis D. Lung dysfunction following cardiopulmonary bypass. J Card Surg. 2010;25:47-55.

37. de Lorgeril M, Salen P, Martin JL, Boucher F, de Leiris J. Interactions of wine drinking with omega- 3 fatty acids in coronary heart disease patients: a fish-like effect of moderate wine drinking. Am Heart J. 2008;155:175-81.

38. di Giuseppe R, de Lorgeril M, Salen P, Laporte F, Di Castelnuovo A, Krogh V, et al. Alcohol consumption and n-3 polyunsaturated fatty acids in healthy men and women from 3 European populations. Am J Clin Nutr. 2009;89:354-62.

39. Eussen SR, Geleijnse JM, Giltay EJ, Rompelberg CJ, Klungel OH, Kromhout D. Effects of n-3 fatty acids on major cardiovascular events in statin users and nonusers with a history of myocardial infarction. Eur Heart J. 2012;33:1582-8.

40. De Caterina R. n-3 Fatty acids in cardiovascular disease. N Engl J Med. 2011; 364:2439-50.

41. Jump DB, Depner CM, Tripathy S. Omega-3 fatty acid supplementation and cardiovascular disease. J Lipid Res. 2012;53:2525-45. 